\title{
The Role of Demographic and Psychological Differences in Future Financial and Economic Expectations
}

\author{
Mahmoud Qadan ${ }^{1} \&$ Uri Ben-Zion ${ }^{1}$ \\ ${ }^{1}$ School of Management, Western Galilee College, Akko, Israel \\ Correspondence: Mahmoud Qadan, School of Management, Western Galilee College, Akko 24121, Israel. Tel: \\ 972-4-901-5216. E-mail: mahmodq@wgalil.ac.il \\ Received: September 10, 2014 \\ doi:10.5539/ijef.v6n12p37 \\ Accepted: October 23, 2014 \\ Online Published: November 25, 2014 \\ URL: http://dx.doi.org/10.5539/ijef.v6n12p37
}

\begin{abstract}
In this study, agents are asked to assess the movements of short and long-term economic and financial variables. These variables include the price level of goods and services, real economic and financial variables. Differently from prior research, this paper investigates short and long run expectations, and tests the influence of racial composition of population on future price expectations. We analyze the agent expectations from further aspects such as age, marital status, working, psychological mood, income and wealth. The findings indicate that expectations are different between demographic groups. Particularly, females tend to expect higher changes almost in the entire tested variables; ethnic minorities systematically report higher expectations; marital status has no impact on future expectations; and working agents tend to be more conservative regarding future changes. In addition, pessimistic agents generally tend to report higher future price movements mainly for gold, interest rates, unemployment and inflation rates.
\end{abstract}

Keywords: forecasting, inflation expectations, perceptions of specific prices, survey data

\section{Introduction}

Price expectation is considered one of the critical variables in an economy. Since the mid-1990s, many central banks have targeted price stability as the primary goal of their monetary policy, as a matter of fact that price and price expectations have important and direct impact on product and financial markets. Many economic authorities use to collect data from business and consumer surveys that address questions on the movement of short-term economic variables such as output, inflation and employment. The financial economic literature emphasizes that forecasting inflation expectations based on consumer surveys have some superiority upon professional and model-based forecasts (see e.g., Ang, Bekaert, \& Wei, 2007; Hafer \& Hein, 1985; Thomas, 1999). Therefore, Practitioners highly appreciate this kind of data, and even treat surveys' results as a leading indicator of the economic activity.

Prior works have intensively studied the issue of inflation expectations via studying the indexed-to-inflation and non-indexed bonds. Other works tested the accuracy and the rationality of various survey measures of inflation expectations. These measures, generally, have a predictive power and indicate a good fit with observable inflation.

Since agents in economy have to make a variety of economic actions such as consumption, saving, investing and borrowing, the issue of expecting economic variables - such as inflation, interest rates on deposits or loans, stock market return and economic growth- becomes crucial. While prior works mainly concentrate on the issue of inflation expectations, this study offers a snapshot on individuals' short and long-run expectations regarding three main variables: goods and services (oil, gold, electricity); real-economic variables: GDP, inflation and unemployment); financial variables (local stock market index; foreign market index; interest rates on: deposits, mortgages, inter-bank interest; exchange rates against the dollar and the euro; housing prices and other variables).

This research differs from prior research in several aspects: while prior works focus on studying inflation only, this article expands the variables of interest to three categories: goods and services, real-economic variables and financial variable. Second, the sample consists of multi-cultural respondents. Third, respondents are all college students that allow controlling the effect of financial literacy. Forth, respondents' psychological mood is also 
considered in order to grasp its impact on individuals' future expectations. This type of data allows us to examine whether various demographic differences have an impact on the perceptions of the expected changes in economy variables. For this purpose, we collected (meanwhile) data from 261 questionnaires. In each questionnaire, individuals are asked to provide their one-year and five-year expectation with respect to the movements of the three types of variables listed above.

The results, by and large, indicate that future expectations are different between agents, and that these differences can stem from factors such as mood, being part of minority, gender, and being employed. More specifically, males tend to be more conservative regarding future price movements, working individuals have lower expectations about future movements of real-economic and financial variable rather than non-employed, psychological mood has also an important role in formatting expectations, i.e., pessimism have a positive impact on the assessment of future prices. Pessimistic respondents tend to expect higher prices for gold and oil compared to optimistic respondents. Finally, belonging to minority feature pushes agents to provide very volatile and higher future expectation. Other factors such as wealth, age, degree of religiosity, marital status, income, and expected income have no clear impact on the individual future price expectations.

The remainder of this study is organized as follows. Section 2 reviews the relevant literature. Section 3 describes the data and develops the method and the econometric model. Section 4 discusses the findings and the empirical implications, and the last section provides a summary and concluding remarks.

\section{Literature Review}

There is an enhanced proliferation in research that deal with the question whether agents in economy are able to detect early signals about future rates of economic growth. Future economic expectations are mainly studied on the base of two research streams. The first is built upon consumer confidence (CC) measures while the second is built upon model-based forecast of standard macro economic variables. Recent academic literature has seen a rise in studies investigating the effect of $\mathrm{CC}$ on stock returns. Actually, measures of consumer confidence have got increasing emphasis as a measure of monitoring consumption trends.

Many works have addressed empirical questions on whether CC is informative of current or future consumption, and whether $\mathrm{CC}$ has any predictive power over and above standard macroeconomic variables. The research shows that $\mathrm{CC}$ is a coincident indicator of consumption growth and income growth as well as changes in housing wealth, inflation, unemployment and real interest rates (Acemoglu \& Scot, 1994). In addition, the hypothesis that CC does not cause GNP (in the Granger sense) is rejected (Matsusaka \& Sbordone, 1995). In addition, CC is Granger-Caused with changes in the capital market (Jansen \& Nahuis, 2003). Measures of CC do forecast future changes in labor earnings and non-stock market wealth, but measures of consumer attitudes appear to be directly related to future consumption growth, not just indirectly through their predictive power for household income or wealth (Ludvigson, 2004). When CC is high, future stock returns tend to be lower and vice versa, and the impact of $\mathrm{CC}$ on returns is stronger for countries that have less well developed market institutions and for countries that are culturally more prone to investor overreaction (Schmeling, 2009).

Prior research find also that $\mathrm{CC}$ measure have a predictive ability with respect to stock market returns (e.g., (Fisher \& Statman, 2003; Brown \& Cliff, 2005) and even more pronouncedly for firms that are hard to price and thus difficult to arbitrage (e.g. Baker \& Wurgler, 2006; Lemmon \& Portniaguina, 2006). There are a negative relationship between the $\mathrm{CC}$ and future stock return. In addition, there is appositive and statistically significant correlation between changes in $\mathrm{CC}$ and the contemporaneous stock returns, high stock return boost the $\mathrm{CC}$ (Fisher \& Statman, 2003).

De Bruin et al. (2010) replicate prior results in the literature (see e.g., Blanchflower \& Coille, 2009; Lombardelli \& Saleheen, 2003) and find that higher inflation expectations are reported by female, poorer, single and less educated. These observed demographic differences in inflation expectations were mostly explained by variations in age and education. They also find relatively higher inflation expectations among respondents who are nonwhite vs. white, single vs. married or living with a partner, low vs. high income, at most high-school educated vs. more educated, and older. De Bruin et al. (2011) allow respondents to report their point forecasts as well as their density forecasts for price and wage inflation. They find that those who express higher levels of expectations also tend to express higher uncertainty in their subjective forecasts, and that heterogeneity in expressed uncertainty is associated with demographic characteristics and financial lriteracy.

Given the importance of price expectations, this study will attempt to extend the literature by addressing more variables than done before in major prior works, and to assess the impact of demographic and psychological differences effect on individual expectations. 


\section{Data and Method}

Our sample consists of 261 respondents from the Western Galilee College and the University of Haifa, in Israel. All participants are students toward the first degree who study in the departments of economics, education and multi-disciplinary studies. This data selection controls the problem of over-estimate inflation of population groups that are without academic education (Mcormack et al., 2009). The age of the participants range from 18 to 54 (Mean=25.3, $\mathrm{SD}=5.51$ ). The population in Israel is constructed of two main nationalities: Jews, as the majority and Arabs, as the minority.

Our method consists of t-tests and econometrical model. The t-tests, intensively utilized in the empirical financial literature, are employed to measure the averages of the variables. The econometric model is based on a linear regression as follows:

$$
Y_{i}=\alpha_{i}+\sum_{i=1}^{N} \beta_{i} x_{i}+\varepsilon_{i},
$$

where $y_{i}$ and $x_{i}$ are the dependent and the independent variable, respectively. As mentioned in the preceding sections, the dependent variable is the individual's one-year and five-year expectation on the rate of change of the level of the following 13 variables: housing, oil, gold, electricity, GDP, unemployment ratio, the local capital market index, U.S capital market index, the interest on deposits, mortgages, inter-bank interest (prime interest), and the exchange rate of dollar and euro currencies against the local currency.

The independent variables include the following dummy variables: gender, marital status, being employed, having apartment-as a proxy for wealth, and belonging to minority. The independent variables include also the following scale variables: psychological mood and religiosity. In addition, we have the following level variables: age and current income in local currency.

For each dependent variable tested, the participant was informed about the level price in the day he fulfilled the questionnaire. Each participant was asked to provide his future expectation regard one year and five years ahead. We then calculate the rate of change for each of the $\mathrm{Y}$ variables.

\section{Empirical Findings}

Table 1 presents some descriptive statistics of the dummy variables. According to this table, the number of participants is 261, among of them 177 are females. Also, 92 of the participants are married, and 171 have a job. Only 42 participants own an apartment, and the majority of the participants are Jews (136) while the rest are Arab.

Table 1. Basic statistics on the participants of the sample

\begin{tabular}{ccccc}
\hline Gender & Marital Status & Work & Apartment & Minority/Majority \\
\hline 177 & 166 & 90 & 42 & 136 \\
Females & Bachelor & Do not work & Own & Jews \\
84 & 92 & 171 & 219 & 125 \\
Males & Married & Have a work & Do not own & Arab \\
& 3 Divorced & & & \\
\hline
\end{tabular}

Note. Table 1 presents basic statistics on the participants of the survey.

Table 2 presents the descriptive statistics of the one-year-ahead expected dependent variables, while table 3 presents the five-year-ahead expected dependent variables. In each table, the variables are categorized into three groups: goods and services, real-economic, and financial variable. According to these tables, the long run expectations are larger than the expectations of one year ahead. 
Table 2. Descriptive statistics of the dependent variables: one-year expectations

Panel A.

\begin{tabular}{cccccccc}
\hline & \multicolumn{3}{c}{ Goods and Services } & \multicolumn{3}{c}{ Real Economic Variables } \\
\cline { 2 - 7 } & Oil Barrel & Gold Ounce & House & Electricity & CPI & GDP & Unemployment \\
\hline average & $7.50 \%$ & $2.84 \%$ & $6.41 \%$ & $9.89 \%$ & $1.74 \%$ & $0.86 \%$ & $2.14 \%$ \\
stdev & $12.08 \%$ & $9.81 \%$ & $12.81 \%$ & $10.25 \%$ & $3.20 \%$ & $4.03 \%$ & $7.51 \%$ \\
max & $60.38 \%$ & $60.17 \%$ & $43.48 \%$ & $78.57 \%$ & $18.77 \%$ & $23.89 \%$ & $7.40 \%$ \\
min & $-19.81 \%$ & $-39.83 \%$ & -26.09 & $-83.93 \%$ & $-8.05 \%$ & $-11.50 \%$ & $-2.00 \%$ \\
median & $3.77 \%$ & $2.20 \%$ & $8.69 \%$ & $7.14 \%$ & $0.57 \%$ & $0.88 \%$ & $1 \%$ \\
\hline
\end{tabular}

Panel B.

\begin{tabular}{cccccccc}
\hline & \multicolumn{7}{c}{ Financial Variables } \\
\cline { 2 - 8 } & $\mathbf{\$ 1}$ & $\boldsymbol{€ 1}$ & $\mathbf{T A - 1 0 0}$ & $\mathbf{S \& P 5 0 0}$ & Mortgage & Deposit & Prime interest \\
\hline average & $1.61 \%$ & $0.20 \%$ & $3.70 \%$ & $24.43 \%$ & $0.33 \%$ & $0.66 \%$ & $0.54 \%$ \\
stdev & $9.67 \%$ & $11.95 \%$ & $18.00 \%$ & $17.43 \%$ & $0.82 \%$ & $1.19 \%$ & $0.90 \%$ \\
$\max$ & $32.98 \%$ & $40.28 \%$ & $59.33 \%$ & $43.54 \%$ & $4.50 \%$ & $8.00 \%$ & $6.00 \%$ \\
$\min$ & $-22.87 \%$ & $-40.08 \%$ & $-25.02 \%$ & $-17.72 \%$ & $-2 \%$ & $-1 \%$ & $-1.25 \%$ \\
median & $1.06 \%$ & $0.20 \%$ & $0.28 \%$ & $33.97 \%$ & $0.2 \%$ & $0.2 \%$ & $0.3 \%$ \\
\hline
\end{tabular}

Note. Table 2 presents the descriptive statistics of dependent variables that are related to one-year ahead expectations. CPI resembles the consumer price index, GDP is the gross domestic product, $1 \$$ is the exchange rate of change of on American dollar against the local currency, $€ 1$ is the exchange rate of change of one euro against the local currency, TA-100 is the leading stock index in Tel-Aviv stock exchange.

Table 3. Descriptive statistics of the dependent variables: five-year expectation

Panel A.

\begin{tabular}{cccccccc}
\hline & \multicolumn{3}{c}{ Goods and Services } & \multicolumn{3}{c}{ Real Economic Variables } \\
\cline { 2 - 7 } & Oil Barrel & Gold Ounce & House & Electricity & CPI & GDP & Unemployment \\
\hline avg & $21.45 \%$ & $15.15 \%$ & $14.73 \%$ & $20.13 \%$ & $7.17 \%$ & $5.36 \%$ & $4.83 \%$ \\
stdev & $26.53 \%$ & $30.89 \%$ & $18.07 \%$ & $21.89 \%$ & $10.05 \%$ & $9.92 \%$ & $10.02 \%$ \\
$\max$ & $88.68 \%$ & $200.84 \%$ & $47.83 \%$ & $69.64 \%$ & $57.47 \%$ & $32.74 \%$ & $7.40 \%$ \\
$\min$ & $-33.96 \%$ & $-39.83 \%$ & $-34.78 \%$ & $-28.57 \%$ & $-5.17 \%$ & $-29.20 \%$ & $-6.00 \%$ \\
median & $22.64 \%$ & $8.30 \%$ & $17.39 \%$ & 21.42 & $4.40 \%$ & $4.42 \%$ & $2 \%$ \\
\hline
\end{tabular}

Panel B.

\begin{tabular}{cccccccc}
\hline & \multicolumn{7}{c}{ Financial Variables } \\
\cline { 2 - 7 } & $\$ \mathbf{1 1}$ & $\boldsymbol{€ 1}$ & TA-100 & S\&P500 & Mortgage & Deposit & Prime interest \\
\hline avg & 5.92 & $6.44 \%$ & $14.54 \%$ & $29.99 \%$ & $1.06 \%$ & $1.71 \%$ & $1.72 \%$ \\
stdev & $19.39 \%$ & $19.04 \%$ & $25.98 \%$ & $21.61 \%$ & $1.77 \%$ & $2.23 \%$ & $2.03 \%$ \\
$\max$ & $59.57 \%$ & $\% 60.32$ & $89.31 \%$ & $62.68 \%$ & $5.40 \%$ & $14.00 \%$ & $11.00 \%$ \\
$\min$ & $-33.51 \%$ & $-39.88 \%$ & $-15.65 \%$ & $-42.58 \%$ & $-4.50 \%$ & $-1.00 \%$ & $-3.50 \%$ \\
median & $6.38 \%$ & $6.21 \%$ & $2.62 \%$ & $35.64 \%$ & $0.5 \%$ & $1 \%$ & $1 \%$ \\
\hline
\end{tabular}

Note. Table 3 presents the descriptive statistics of dependent variables that are related to one-year ahead expectations. The notations are as in Table 2 .

Table 4 presents the estimations results of Eq. (1). This equation has been estimated several times in order to explore specification errors. That is, Eq. (1) included in the first estimation all the candidate explanatory variables, whereas eventually the list of good fit explanatory variables was reduced to only 4 variables: gender, belonging to minority, having a work, and psychological mood level. That is, 


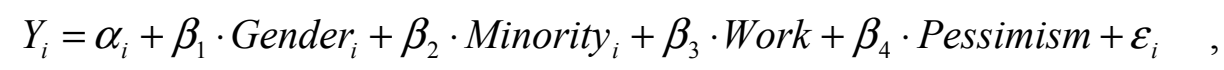

In each questionnaire there are 9 questions that address the issue of pessimism. Those questions are formed as 1-to-5-scale questions in order to reflect the mood of individuals. For each questionnaire we calculated the average of these nine questions, and the received average value was employed as a proxy of individual mood. This average value was utilized as an explanatory variable.

Table 4. Estimation results of Eq. (1)

\begin{tabular}{|c|c|c|c|c|c|c|}
\hline & Gender & Minority & Work & Pessimism & $\mathrm{R}^{2}$ & $\mathrm{~F}$ \\
\hline \multicolumn{7}{|l|}{ Goods and Services } \\
\hline Hosing: One-Year Expectation & $-0.079 * * *$ & 0.031 & -0.010 & $0.036 * * *$ & 0.136 & $16.02 * * *$ \\
\hline Five-Year Expectation & $-0.225 * * *$ & $0.146^{*}$ & -0.094 & $0.160 * * *$ & 0.176 & $28.09 * * *$ \\
\hline Oil: One-Year Expectation & $-0.071 * * *$ & 0.037 & 0.019 & $0.045^{* * *}$ & 0.060 & $15.35 * * *$ \\
\hline Five-Year Expectation & -0.142 & $0.276 * * *$ & 0.135 & $0.103 * * *$ & 0.066 & $18.98 * * *$ \\
\hline Gold: One-Year Expectation & -0.019 & $0.037 * * *$ & 0.010 & 0.002 & 0.018 & $3.55^{* * *}$ \\
\hline Five-Year Expectation & -0.086 & 0.025 & $-0.150 * * *$ & $0.113 * * *$ & 0.116 & $13.03 * * *$ \\
\hline Electricity: One-Year Expectation & 0.021 & -0.026 & 0.025 & $0.040 * * *$ & 0.010 & $19.91 * * *$ \\
\hline Five-Year Expectation & 0.010 & $0.091 *$ & $0.119 * * *$ & 0.025 & 0.001 & $16.30 * * *$ \\
\hline \multicolumn{7}{|l|}{ Real Economic Variables } \\
\hline GDP: One-Year Expectation & 0.013 & -0.008 & 0.004 & 0.000 & 0.011 & 0.77 \\
\hline Five-Year Expectation & -0.003 & 0.036 & 0.037 & 0.014 & 0.029 & $5.69 * * *$ \\
\hline Unemployment: one year Expectation & -1.049 & 1.622 & -0.315 & 0.706 & 0.010 & $3.94 * * *$ \\
\hline Five-Year Expectation & -2.507 & 2.939 & -0.300 & 1.806 & 0.048 & $12.93 * * *$ \\
\hline CPI: One-Year Expectation & $-0.050 * * *$ & 0.007 & 0.009 & $0.023 * * *$ & 0.036 & $5.42 * * *$ \\
\hline Five-Year Expectation & $-0.093 *$ & 0.004 & 0.086 & $0.045^{* * *}$ & 0.034 & $8.55 * * *$ \\
\hline \multicolumn{7}{|l|}{ Financial Variables } \\
\hline TA100: One-Year Expectation & -0.057 & 0.016 & -0.027 & 0.026 & 0.063 & $4.07 * * *$ \\
\hline Five-Year Expectation & -0.078 & 0.101 & 0.017 & 0.067 & 0.033 & $10.69 * * *$ \\
\hline SP500: One-Year Expectation & $0.098 * * *$ & 0.066 & $0.163 * * *$ & 0.015 & 0.038 & $36.41 * * *$ \\
\hline Five-Year Expectation & 0.103 & 0.056 & $0.152 * * *$ & $0.065 * * *$ & 0.031 & $32.45 * * *$ \\
\hline Mortgage: One-Year Expectation & $-0.344 * * *$ & $0.283 * * *$ & 0.037 & $0.110 * * *$ & 0.102 & $9.80 * * *$ \\
\hline Five-Year Expectation & $-0.836 * * *$ & $1.106 * * *$ & -0.055 & $0.349 * * *$ & 0.119 & $15.50 * * *$ \\
\hline Deposit (interest): One-Year Expectation & -0.075 & 0.262 & -0.058 & $0.218 * * *$ & 0.052 & $17.08 * * *$ \\
\hline Five-Year Expectation & -0.471 & $0.806 * * *$ & -0.138 & $0.590 * * *$ & 0.116 & $32.24 * * *$ \\
\hline Prime (interest): One-Year Expectation & $-0.335 * * *$ & 0.277 & -0.082 & 0.197 & 0.143 & $23.04 * * *$ \\
\hline Five-Year Expectation & $-0.760 * * *$ & $0.726 * * *$ & $-0.482 *$ & $0.688 * * *$ & 0.216 & $17.39 * * *$ \\
\hline \$ Exchange rate: One-Year Expectation & -0.011 & $0.041 * * *$ & -0.010 & $0.018 * * *$ & 0.028 & $2.72 * * *$ \\
\hline Five-Year Expectation & -0.084 & -0.051 & -0.062 & $0.084 * * *$ & 0.042 & $8.30 * * *$ \\
\hline$€$ Exchange rate: One-Year Expectation & $-0.049 * * *$ & 0.004 & -0.033 & $0.016 * * *$ & 0.065 & $3.20 * * *$ \\
\hline Five-Year Expectation & $-0.147 * * *$ & 0.025 & -0.047 & $0.076 * * *$ & 0.119 & $1.89 * * *$ \\
\hline
\end{tabular}

Note. Table 4 reports the estimation results of Eq. (1). $(* * *),(* *)$ and $(*)$ indicate significance at the levels of $1 \% 5 \%$ and $10 \%$, respectively.

Table 4 shows that $\beta_{1}$ coefficient is generally negative. $\beta_{1}$ coefficient quantifies the impact of gender on the expectations of individual i. Of 26 values of the $\beta_{1}$ coefficients, there are 21 negative values. 12 of them are statistically significant. This finding implies that there is a significant difference between the expectations between males and females. More specifically, males tend to lower their expectation regarding future movements in the variables tested (except for their expectations regard the S\&P500).

$\beta_{2}$ assesses the impact of being a minority member on the individual's expectations. Table 4 shows also that $\beta_{2}$ is mainly positive. Of 26 values of the $\beta_{2}$ coefficients, 23 are positively signed and only 4 are negative. For 9 cases $\beta_{2}$ is statistically significant. This finding is in line with Bryan and Venkatu (2001) and Bruin et al. (2010). They argue that racial ethnic minorities (non-white vs. white participants) systematically report higher, and sometimes unrealistic, inflation expectations. Our findings show that minority's expectations are higher not only for inflation expectations, but also for other several economic and financial variables.

We find also that individuals that have a work (job), and consequently have higher income, tend to lower their 
future expectations about movements in the economy variables, as appears in the negative $\beta_{3}$ coefficients as appears in Table 4. $\beta_{3}$ receives negative values for 15 cases, while for 11 cases the coefficient is negative. This finding is in line with Zikmund et al. (1999), according to which low-income populations tend to be more myopic when making financial decisions. Also, individuals who report higher inflation expectations may have shorter financial planning horizons. These population groups seems to be more sensitive to transient price shocks as well as less informed about the longer-term price trends captured in the inflation rate (Bruin, 2010).

The proxy measure of individuals' pessimism tends to push the future expectations up as reported by the $\beta_{4}$ coefficients. The $\beta_{4}$ coefficient estimates the impact of pessimism level on individual's future expectations. $\beta_{4}$ coefficients are significantly positive in most cases. The interpretation of this finding can be related to other observed fact according to which, pessimistic individuals provide higher absolute changes. In addition, pessimism is highly linked to the minority respondents. We compared between the psychological mood of majority and minority respondents by the following two equations.

$$
\begin{aligned}
& \text { Optimism }=\theta_{0}+\theta_{1} \text { Minority }_{\mathrm{i}} \text {, } \\
& 4.107 \quad-0.322 \\
& \text { (78.19) (-4.03) }
\end{aligned}
$$

where optimism is a scale variable calculated by taking the average of 7 questions that addressed optimism, and minority $_{i}$ is a dummy variable which receives the value of 1 if the respondent belongs to minority in the population. The estimation result shows that $\theta_{1}$ is positive and statistically significant, indicating that the optimism level is lower for minority respondents. In addition, we run the following equation:

$$
\begin{gathered}
\text { Pessimism }_{\mathrm{i}}=\theta_{0}+\theta_{1} \cdot \text { Minority }_{\mathrm{i}}, \\
2.308 \quad 0.655
\end{gathered}
$$

Where pessimism is also a scale variable calculated by taking the average of 9 questions that address pessimism. The results of Equations 2 and 3 reveal an interesting finding. They indicate that individuals belonging to minority are less optimistic, or stating differently, more pessimistic.

The results in Table 4 are relatively well explained for case of the financial and for the goods variables. However, the real-economic variables are weakly explained by the proposed explanatory variables.

Another insight on the differences between expectations of majority vs. minority is given in table 5. The table provides the t-test result on whether individuals that belong to minority have systematically higher values of future expectations rather than the majority.

Table 6 reports the relationship between optimism level of individuals and their expectations regarding movements in stock market index. The results are statistically significant (for the S\&P 500) and show that optimism positively affect the expectations on movements in the capital market. Table 7 reports the correlation between individuals' pessimism level and their expectation regarding movements in capital market index. We find that pessimism has a negative affect (as expected) on the future expected movements in the market index.

Table 5. Differences in expectations of majority vs. minority individuals in (\%)

\begin{tabular}{llccc}
\hline & & Majority & Minorities & T-test Value \\
\hline Unemployment & one-year expectation & 1.66 & 2.58 & 0.945 \\
Prime Interest & five year-expectation & 3.87 & 5.87 & $2.20^{* * *}$ \\
one-year expectation & 0.348 & 0.784 & $3.49^{* * *}$ \\
Mortgage & five year-expectation & 1.003 & 4.409 & $4.68^{* * *}$ \\
& one-year expectation & 0.154 & 0.523 & $2.97 * * *$ \\
One-Year Deposit & five year-expectation & 0.579 & 1.581 & $3.42^{* * *}$ \\
& one-year expectation & 0.44 & 0.896 & $2.73^{* * *}$ \\
Housing & five year-expectation & 1.215 & 2.642 & $3.93^{* *}$ \\
Oil Barrel & one-year expectation & 4.30 & 11.88 & $2.04^{* * *}$ \\
& five year-expectation & 11.17 & 14.73 & $2.41^{* * *}$ \\
Gold -One Ounce & one-year expectation & 5.63 & 9.33 & $1.97 * *$ \\
\hline
\end{tabular}




\begin{tabular}{llccc}
\hline \multirow{3}{*}{ Tel-Aviv stock exchange index } & five year-expectation & 12.79 & 17.70 & $1.78^{* *}$ \\
& one-year expectation & 0.37 & 1.96 & 1.10 \\
& five year-expectation & 13.37 & 16.06 & 0.63 \\
S\&P 500 index & one-year expectation & 25.15 & 23.41 & -0.62 \\
& five year-expectation & 32.34 & 26.46 & -1.68 \\
CPI & one-year expectation & 1.61 & 1.88 & 0.70629 \\
& five year-expectation & 6.7 & 7.67 & 1.05708 \\
Dollar Exchange rate & one-year expectation & 3.13 & 3.94 & -1.18 \\
& five year-expectation & 5.01 & 6.91 & 0.6224 \\
Euro Exchange Rate & one-year expectation & -0.32 & 0.76 & 1.2179 \\
\multirow{2}{*}{ GDP } & five year-expectation & 5.82 & 7.11 & $2.12^{* * *}$ \\
& one-year expectation & 1.80 & -0.18 & -1.18279 \\
Electricity one KW/H & five year-expectation & 4.17 & 6.64 & $1.98^{* * *}$ \\
& one-year expectation & 8.44 & 11.46 & 0.4997 \\
\hline
\end{tabular}

Note. Table 5 reports the differences of future expectation of majority versus minority individuals. $(* * *),(* *)$ and $(*)$ indicate significance at the levels of $1 \% 5 \%$ and $10 \%$, respectively.

Table 6. Relationship between capital market index and individual's optimism

\begin{tabular}{lcccc}
\hline Dependent Variable & alpha & beta & $\mathrm{R}^{2}$ & $\mathrm{~F}$ \\
\hline TA-100 & 0.115 & -0.0192 & 0.004 & 0.75 \\
TA-100 (5-Year Forecast) & 0.11 & 0.0265 & 0.001 & 0.26 \\
S\&P 500 & -0.0245 & $0.0652^{* * *}$ & 0.027 & 0.75 \\
S\&P 500 (5-Year Forecast) & -0.113 & $0.116^{* * *}$ & 0.03 & $6.6^{* * *}$ \\
\hline
\end{tabular}

Note. Table 6 presents the estimation results of the equation $Y_{i}=a_{i}+\beta \cdot$ Optimism $+\varepsilon_{i}$. The beta coefficient links the Optimism measure to the future expectation of individuals. TA-100 denotes the (domestic) Tel-Aviv 100 stock index. (***), (**) and (*) indicate significance at the levels of $1 \% 5 \%$ and $10 \%$, respectively.

It is commonly argued in the literature that during a pessimistic periods (e.g., crises, wars, capital market crashes and hyper-inflation) substantial speculative capital flows are diverted to durable goods, among them, and maybe the most prominent of which, is gold. Recent literature relates part of the change in gold price to psychological sentiments. More specifically, it is argued that gold price is driven by the Volatility Index (VIX) which is widely considered as an indicator of pessimism sentiment of the market participants (Qadan \& Yagil, 2012). In addition, gold acts as a safe haven asset, offering protection to investors against losses in financial markets (Baur \& McDermott, 2010). We test whether bad psychological mood of respondents forecast a positive change in gold price. For this sake, we run the following regression model:

$$
\begin{array}{cc}
\text { Gold }_{\mathrm{i}}=\theta_{0}+\theta_{1} \cdot \text { Psmsm }_{\mathrm{i}}, \\
-0.159 & 0.130 \\
(-1.524) & (3.319)
\end{array}
$$

where Gold is the long-run rate of change in the expected price of gold provided by respondent $i$, and $\mathrm{Psmsm}_{\mathrm{i}}$ is the level of pessimism of respondent $i$. The estimation result in Eq. (4) shows that $\theta_{1}$ is positive and is statistically significant, indicating that pessimism level pushes gold price upward. This finding is in line with prior research according to which market participants fear sentiments about dropping prices in the capital market are associated with rising in gold price. This finding may strengthen the claim that gold acts as a safe haven asset, offering protection to investors against losses in financial markets. 
Table 7. Relationship between capital market index and individual's pessimism

\begin{tabular}{lllll}
\hline Dependent Variable & alpha & beta & $\mathrm{R}^{2}$ & $\mathrm{~F}$ \\
\hline TA-100 & -0.027 & 0.026 & 0.01 & 1.87 \\
TA-100 (5-Year Forecast) & 0.100 & 0.046 & 0.006 & 1.01 \\
S\&P 500 & $0.492^{* * *}$ & $-0.099^{* * *}$ & 0.079 & $14.98^{* * *}$ \\
S\&P 500 (5-Year Forecast) & $0.536^{* * *}$ & $-0.072^{*}$ & 0.018 & $3.23^{*}$ \\
\hline
\end{tabular}

Note. Table 7 presents the estimation results of the following equation. $Y_{i}=a_{i}+\beta \cdot$ Passimism $_{i}+\mathcal{E}_{i}$. The explanatory variable is the pessimism measure. Hence, beta links the pessimism sentiments to the future expectations. $(* * *),(* *)$ and $(*)$ indicate significance at the levels of $1 \% 5 \%$ and $10 \%$, respectively.

\section{Concluding Remarks}

It has been lengthily argued that expectations about future inflation are generally important for households' decisions about spending and saving, and for central bankers for calibrating monetary policy. However, since agents in economy make a variety of economic decisions about consumption, saving, investing and borrowing, among other things, the issue of individual economic expectation of other economic and financial variables becomes crucial.

This paper offers an extension to the issue of individual's price expectations. While prior works on economic expectations focused mainly on forecasting inflation, little is known about forecasting movements of other important variables in the economy. Specifically, instead of focusing on one variable only (the inflation), we extend the variables of interest to three categories: goods and services, real-economic variables and financial variables. These variables had been studied in the context of short and long-run. For this purpose, we constructed questionnaires that address the issue individual's expectations with respect to the variables listed above.

The findings indicate that expectations among individuals are different, but can be described as follows: males' expectations are more conservative comparing with females; working respondents report lower price expectation relative to non-working respondents; Arab individuals (as the minority in the population) report systematically higher expectations comparing with the majority of the population. The significant tendency of minority agents to highly expect future changes can be related to other observed phenomenon according to which minority respondents are more (less) pessimistic (optimistic) comparing to the majority. In addition, pessimistic agents have a clear tendency to report higher gold price expectations. This finding is in line with the claim that gold can be substitute and safe haven investment vehicle in periods of instability.

\section{References}

Acemoglu, D., \& Scott, A. (1994). Consumer confidence and rational expectations: are agents' beliefs consistent with the theory? The Economic Journal, 1-19. http://dx.doi.org/10.2307/2234671

Ang, A., Bekaert, G., \& Wei, M. (2007). Do macro variables, asset markets, or surveys forecast inflation better? Journal of Monetary Economics, 54(4), 1163-1212. http://dx.doi.org/10.1016/j.jmoneco.2006.04.006

Baker, M., \& Wurgler, J. (2006). Investor sentiment and the cross - section of stock returns. The Journal of Finance, 61(4), 1645-1680. http://dx.doi.org/10.1111/j.1540-6261.2006.00885.x

Baur, D. G., \& McDermott, T. K. (2010). Is gold a safe haven? International evidence. Journal of Banking \& Finance, 34(8), 1886-1898. http://dx.doi.org/10.1016/j.jbankfin.2009.12.008

Blanchflower, D. G., \& MacCoille, C. (2009). The formation of inflation expectations: an empirical analysis for the UK (No. w15388). National Bureau of Economic Research.

Brown, G. W., \& Cliff, M. T. (2005). Investor Sentiment and Asset Valuation. The Journal of Business, 78(2), 405-440. http://dx.doi.org/10.1086/427633

Bryan, M. F., \& Venkatu, G. (2001). The demographics of inflation opinion surveys. Federal Reserve Bank of Cleveland, Research Department.

De Bruin, W. B., Vanderklaauw, W., Downs, J. S., Fischhoff, B., Topa, G., \& Armantier, O. (2010). Expectations of inflation: The role of demographic variables, expectation formation, and financial literacy. Journal of Consumer Affairs, 44(2), 381-402. http://dx.doi.org/10.1111/j.1745-6606.2010.01174.x

De Bruin, W. B., Manski, C. F., Topa, G., \& Van der Klaauw, W. (2011). Measuring consumer uncertainty about future inflation. Journal of Applied Econometrics, 26(3), 454-478. http://dx.doi.org/10.1002/jae.1239 
Fisher, K. L., \& Statman, M. (2003). Consumer confidence and stock returns. The Journal of Portfolio Management, 30(1), 115-127. http://dx.doi.org/10.3905/jpm.2003.319925

Hafer, R. W., \& Hein, S. E. (1985). On the accuracy of time-series, interest rate, and survey forecasts of inflation. Journal of Business, 377-398. http://dx.doi.org/10.1086/296304

Jansen, W. J., \& Nahuis, N. J. (2003). The stock market and consumer confidence: European evidence. Economics Letters, 79(1), 89-98. http://dx.doi.org/10.1016/S0165-1765(02)00292-6

Lemmon, M., \& Portniaguina, E. (2006). Consumer confidence and asset prices: Some empirical evidence. Review of Financial Studies, 19(4), 1499-1529. http://dx.doi.org/10.1093/rfs/hhj038

Lombardelli, C., \& Saleheen, J. (2003). Public expectations of UK inflation. Bank of England Quarterly Bulletin, 43(3), 281-290.

Ludvigson, S. C. (2004). Consumer confidence and consumer spending. Journal of Economic Perspectives, 2950. http://dx.doi.org/10.1257/0895330041371222

Matsusaka, J. G., \& Sbordone, A. M. (1995). Consumer confidence and economic fluctuations. Economic Inquiry, 33(2), 296-318. http://dx.doi.org/10.1111/j.1465-7295.1995.tb01864.x

McCormack, L., Bann, C., Uhrig, J., Berkman, N., \& Rudd, R. (2009). Health insurance literacy of older adults. Journal of Consumer Affairs, 43(2), 223-248. http://dx.doi.org/10.1111/j.1745-6606.2009.01138.x

Qadan, M., \& Yagil, J. (2012). Fear sentiments and gold price: testing causality in-mean and in-variance. Applied Economic Letters, 19, 363-366. http://dx.doi.org/10.1080/13504851.2011.579053

Schmeling, M. (2009). Investor sentiment and stock returns: Some international evidence. Journal of Empirical Finance, 16(3), 394-408. http://dx.doi.org/10.1016/j.jempfin.2009.01.002

Thomas, L. B. (1999). Survey measures of expected US inflation. The Journal of Economic Perspectives, 125144. http://dx.doi.org/10.1257/jep.13.4.125

Zikmund-Fisher, B. J., \& Parker, A. M. (1999). Demand for rent-to-own contracts: a behavioral economic explanation. Journal of Economic Behavior \& Organization, 38(2), 199-216. http://dx.doi.org/10.1016/S0167-2681(99)00006-2

\section{Copyrights}

Copyright for this article is retained by the author(s), with first publication rights granted to the journal.

This is an open-access article distributed under the terms and conditions of the Creative Commons Attribution license (http://creativecommons.org/licenses/by/3.0/). 